\title{
Avulsion of left main coronary artery stent-Rare but recognised entity
}

\author{
Santosh K Sinha*, Vinay Krishna and Umeshwar Pandey \\ Department of Cardiology, LPS Institute of Cardiology, G.S.V.M. Medical College, Kanpur, Uttar Pradesh, India
}

\begin{abstract}
Coronary stent fracture, discontinuation of any part of the stent structure, albeit rare but is an important and under reported complication. It has been described rarely in left main coronary artery (LMCA). Here, we describe a case of 49-year-old male who presented with intractable exertional angina. His left main had been stented 8 months ago with $3.5 \times 23 \mathrm{~mm}$ Xience Prime everolimus eluting stent (Abott Vasc, USA). Check angiogram revealed critical in-stent restenosis (ISR) of LMCA stent in osteo-proximal part along with avulsion of stent (stent fracture) was noted in its proximal part. Repeat intervention was performed with $3.5 \times 12$ mm Endeavour Resolute Zotarolimus eluting stent (Medtronic, USA) after aggressive pre-dilatation with Flextome cutting balloon (Boston Scientific, USA). To best of our knowledge, it is first ever case report of avulsion of left main stent.
\end{abstract}

\section{Introduction}

The journey of percutaneous coronary interventions started from plain old balloon angioplasty and ended to bio resolvable vascular scaffold, stopping in between at bare metal stents (BMS) and drug eluting stent (DES) with new complication emerging at each step. Coronary stent fracture is defined as a discontinuation of any part of the stent structure seen on angiogram. Stent fracture albeit rare, is important and under reported complications of PCI [1,2]. It was first described with bare-metal stents in 2002, followed by with DES in 2004 $[3,4]$. Its incidence varies from $0.8-19 \%$ because of most of them are asymptomatic. Newer designs, materials, and eluting drugs are being developed to improve the performance, safety, and long-term patency of drug-eluting stents (DES). Disease of left main coronary artery (LMCA) is considered the highest risk coronary artery disease subtype and is associated with a poorer prognosis than involvement of any other territory. PCI involving the LMCA were associated with considerable risks of acute complications and early mortality, as well as long-term restenosis [5].

\section{Case presentation}

A 49-year-old male, smoker presented with acute coronary syndrome- unstable angina. Coronary angiography was performed after proper consent which revealed significant disease of whole LMCA $(>50 \%)$ with critical stenosis of proximal left anterior descending (LAD) artery (Figure 1A). PCI was subsequently planned. Left main artery was cannulated with 7F Judkins left (JL) guiding catheter. Sion black (Ashahi, Japan) wire was parked into LAD and left circumflex artery (LCx), and third wire was floated into aortic sinus as a saple wire in order to prevent deep cannulation of LMCA. Lesion was predilated with 3x10 mm Sapphire semi compliant balloon (Orbus Neisch, Netherland). 3.5x23 mm Xience Prime everolimus eluting stent (Abott Vasc, USA) was deployed at $13 \mathrm{~atm}$ pressure (Figure 1B). Stent balloon was further pulled up into aortic sinus and proximal edge of stent was flared at $15 \mathrm{~atm}$ pressure achieving TIMI III flow (Figure 1C). It was

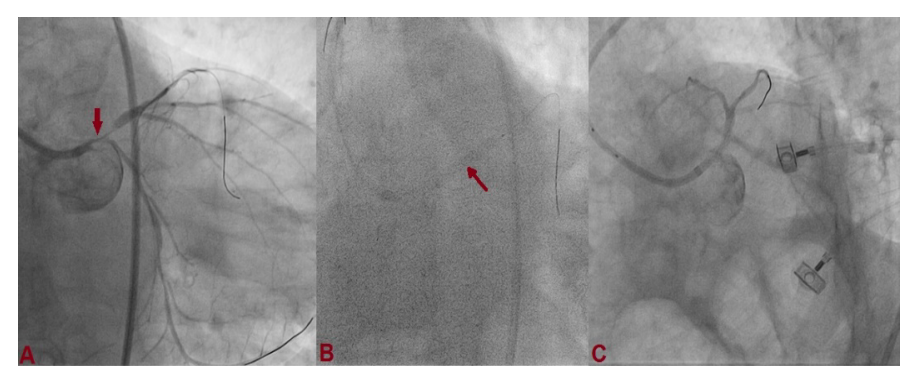

Figure 1. Coronary angiography revealing significant disease of whole LMCA with critica stenosis of proximal LAD (A); $3.5 \times 23 \mathrm{~mm}$ Xience Prime everolimus eluting stent was deployed at $13 \mathrm{~atm}$ pressure (B); TIMI III flow following PCI

further post dilated with $4 \times 10 \mathrm{~mm}$ Sapphire non-compliant balloon at $15 \mathrm{~atm}$ pressure. He was discharged in stable condition with prasugrel $10 \mathrm{mg}$, aspirin-75 mg, rosuvastatin- $40 \mathrm{mg}$, metoprolol-100 $\mathrm{mg}$, and ramipril-10 $\mathrm{mg}$.

8 months later, patient started complaining of exertional angina despite optimal medical treatment. Check angiogram revealed critical in-stent restenosis (ISR) of LMCA stent in osteo-proximal part. Repeat PCI was planned. Difficulty was encountered while cannulating LMCA but somehow could be cannulated with JL guide catheter. Sion black wire was not getting advanced into LAD beyond the guide catheter. After lot of maneuverability, wire could be parked into distal LAD. On careful analysis, stent fracture was noted in its proximal part (Figure 2). Stent was predilated with $2.5 \times 10$ and $3 \times 10 \mathrm{~mm}$ Flextome cutting balloon (Boston Scientific, USA) (Figure 3A). Another 3.5x12 mm

${ }^{\star}$ Correspondence to: Santosh Kumar Sinha, Department of Cardiology, LPS Institute of Cardiology, G.S.V.M. Medical College, Kanpur, Uttar Pradesh, India, E-mail: fionasan@rediffmail.com

Key words: stent fracture, exertional angina, stent avulsion, in-stent restenosis Received: April 17, 2020; Accepted: April 24, 2020; Published: April 30, 2020 
Endeavour Resolute Zotarolimus eluting stent (Medtronic, USA) was deployed (Figure $3 \mathrm{~B}$ ), and post dilated with $4 \times 10 \mathrm{~mm}$ Sapphire noncompliant balloon (Figure 4A). Post procedure, TIMI III flow was noted (Figure 4B). He was discharged in stable condition with ticagrelor$180 \mathrm{mg}$, aspirin-75 mg, rosuvastatin- $40 \mathrm{mg}$, metoprolol-100 $\mathrm{mg}$, and ramipril-10 $\mathrm{mg}$. He is stable and doing fine on regular follow up.

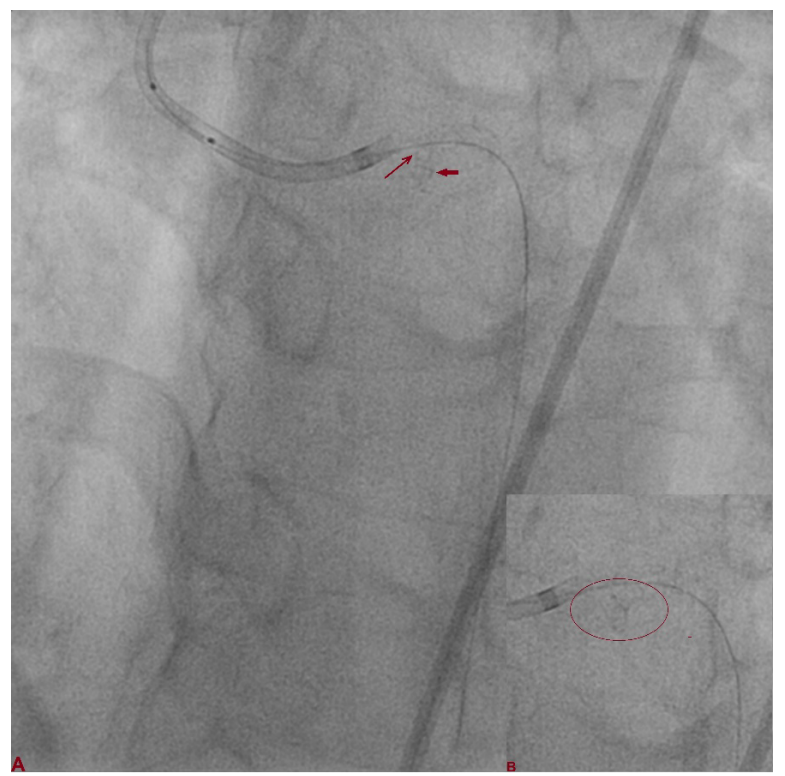

Figure 2. In-stent restenosis of LMCA stent in osteo-proximal part with stent fracture was noted in its proximal part $(\mathrm{A}, \mathrm{B})$

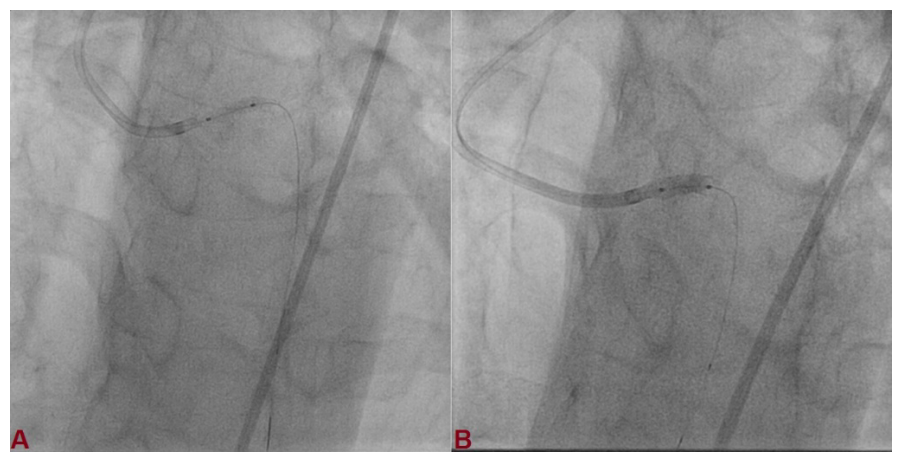

Figure 3. Stent was predilated with Flextome cutting balloon (A); 3.5x12 mm Endeavour Resolute Zotarolimus eluting stent was deployed (B)

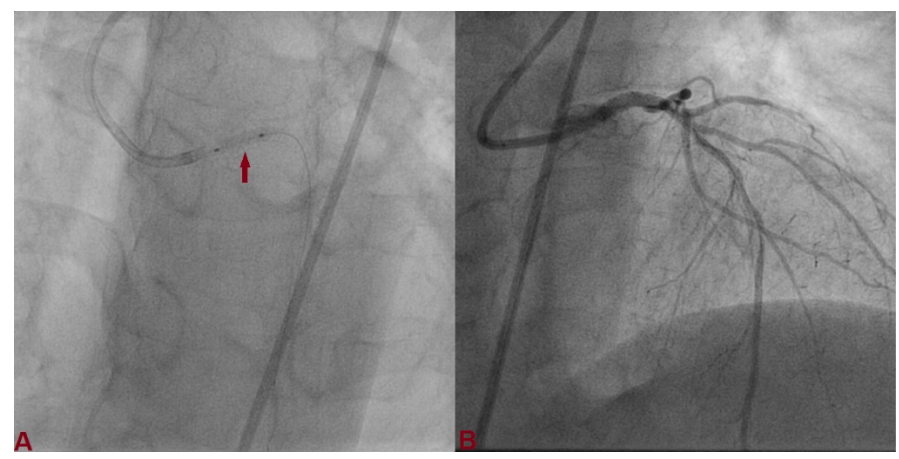

Figure 4. Stent was post dilated with $4 \times 10 \mathrm{~mm}$ Sapphire non-compliant balloon (A); Post procedure, TIMI III flow was noted (B).

\section{Discussion}

Repetitive cardiac contractions leads to mechanical stretching of coronary stents while body movements lead to conformational changes producing axial stress to stents in peripheral vessels such as the femoral, popliteal, and carotid. Propensity to fracture also depends on the anatomic location and its physiological milieu. This produces areas on the stent where greater stress will be localized. External forces from the movement of organs also place additional stress on these stents. These factors make RCA more vulnerable to stent fracture.

In a meta-analysis by Chakraborty et al on-stent fracture, the incidence rates of this complication in the RCA, LAD, LCx, saphenous vein graft, and left main artery were $56.4 \%, 30.4 \%, 10.9 \%, 1.7 \%$, and $\leq$ $0.01 \%$, respectively. Fractures may lead to acute coronary syndrome, instent restenosis, thrombosis (acute, sub-acute or late), pseudoaneurysm formation, embolization and sudden death resulting in both shortand long-term morbidity and mortality [6]. Coronary stent fracture (SF) has been classified on the basis of separation site of stent struts and the displacement of the fractured stent which can be disruption type (minor or single strut), avulsion (moderate), and displacement (severe) as described by Chung et al. [7]. Alternatively, they have also been classified by Adlakha et al which considers strut fracture and displacement [8]. Both the schema ate based on fluoroscopic descriptions, but they lack the luminal information in relation to the SF. An alternative morphological classification has also been proposed using cineangiography and intravascular ultrasound (IVUS) for coronary stent fractures by Carter et al which also gives information about ISR and other complications that may occur as result of SF [9]. ISR associated with SF is thought to occur due to drug maldistribution and neointimal hyperplasia because mechanical irritation triggered by fractured struts. Furthermore, free metal strut exposed into the lumen may trigger platelet activation resulting in thrombosis [10-12].

ISR, either focal or diffuse may be associated with recurrence of symptoms and increased need for target vessel revascularization. Focal stenosis related to SF is mostly seen in the middle portion of the stent as in our case. Excess overhang may be the one of the contributing factors. Placement of stent in case of ostial LMCA stent has to be accurate as slight geographical miss may trigger ISR or stent thrombosis. Also, aorto-ostial fibre at LMCA ostia behaves differently which might have been the reason. The treatment of coronary SF is dependent on the clinical presentation. Asymptomatic patients without restenosis can be followed closely without intervention; however, extension of dual antiplatelet therapy beyond 1 year might be considered. If symptoms become present, further intervention should be sought. The stent-instent technique is commonly employed when symptoms are present and the fracture is associated with restenosis. The superiority of plain old balloon angioplasty (POBA), BMS placement, use of DES (homo or hetero), or recently drug eluting balloon (DEB) in treating these fractures is unknown.

\section{Conclusion}

Coronary stent fracture is one of the dreaded complications of PCI which has been exceedingly rare in left main coronary artery (LMCA). It can be easily salvaged by percutaneous technique. To best of our knowledge, it is first ever case report of avulsion of left main stent.

\section{Disclosures}

No disclosures. 


\section{Competing Interests}

The authors have no competing interests to report.

\section{Funding}

This research did not receive any specific grant from funding agencies in the public, commercial, or not-for-profit sectors.

\section{References}

1. Ino Y, Toyoda Y, Tanaka A, Ishii S, Kusuyama Y, et al. (2009) Predictors and prognosis of stent fracture after sirolimus-eluting stent implantation. Circ J 73: 2036-2041. [Crossref]

2. Canan T, Lee MS (2010) Drug-eluting stent fracture: incidence, contributing factors, and clinical implications. Catheter Cardiovasc Interv 75: 237-245. [Crossref]

3. Chowdhury PS, Ramos RG (2002) Images in clinical medicine: coronary-stent fracture. N Engl J Med 347: 581. [Crossref]

4. Sianos G, Hofma S, Ligthart JMR, Saia F, Hoye A, et al. (2004) Stent fracture and restenosis in the drug-eluting stent era. Catheter Cardiovasc Interv 61: 111-116. [Crossref]

5. Buszman PE, Kiesz SR, Bochenek A, Peszek-Przybyla E, Szkrobka I, et al. (2008) Acute and late outcomes of unprotected left main stenting in comparison with surgical revascularization. J Am Coll Cardiol 51: 538-545. [Crossref]
6. Okamura T, Hiro T, Fujii T, Yamada J, Fukumoto Y, et al. (2008) Late giant coronary aneurysm associated with a fracture of sirolimus eluting stent: A case report. $J$ Cardiol 51: 74-79. [Crossref]

7. Liao R, Green NE, Chen SY, Messenger JC, Hansgen AR, et al. (2004) Threedimensional analysis of in vivo coronary stent-coronary artery interactions. Int $J$ Cardiovasc Imaging 20: 305-313. [Crossref]

8. Chung WS, Park CS, Seung KB, Kim PJ, Lee JM, et al. (2008) The incidence and clinical impact of stent strut fractures developed after drug eluting stent implantation. Int J Cardiol 125: 325-331. [Crossref]

9. Adlakha S, Sheikh M, Bruhl S, Eltahawy E, Pandya U, et al. (2010) Coronary stent fracture: a cause of cardiac chest pain? Int J Cardiol 141: e23-25. [Crossref]

10. Carter AJ (2008) Stent strut fracture: Seeing is believing. Catheter Cardiovasc Interv 71: 619-620. [Crossref]

11. Okumura M, Ozaki Y, Ishii J, Kan S, Naruse H, et al. (2007) Restenosis and stent fracture following sirolimus- eluting stent (SES) implantation. Circ J 71: 1669-1677. [Crossref]

12. Chakravarty T, White AJ, Buch M, Naik H, Doctor N, et al. (2010) Meta-analysis of incidence, clinical characteristics and implications of stent fracture. Am J Cardiol 106: 1075-1080. [Crossref]

Copyright: $\odot 2020$ Sinha SK. This is an open-access article distributed under the terms of the Creative Commons Attribution License, which permits unrestricted use, distribution, and reproduction in any medium, provided the original author and source are credited. 